\title{
Bone marrow cellularity assessed by point-counting
}

\author{
D. O. HO-YEN AND W. SLIDDERS
}

\begin{abstract}
From the Department of Pathology, University of Dundee, Ninewells Hospital and Medical School, Dundee, UK
\end{abstract}

SUMMARY A simple method for rapid point-counting of bone marrow biopsies is described; the method gave an accurate assessment of cellularity in 100 aspiration biopsy specimens. Measurements of marrow cellularity by the visual point-counting technique correlated well with those obtained with a Quantimet 720 image-analysing computer.

The assessment of bone marrow cellularity is essential in the diagnosis of marrow hypoplasia or aplasia (de Gruchy, 1970) and also in the differentiation of polycythaemia vera from secondary erythrocytosis (Kurnick et al., 1972).

Evaluation of the cellularity of biopsies is usually based on the microscopist's experience rather than on objective criteria. Morley and Blake (1975) compared direct visual assessment of marrow cellularity in the mouse with the nucleated cell count in suspensions of whole marrow and found that the former method failed to distinguish between many normal and abnormal marrows. Nearly all cases of mild or moderate hypocellularity were missed, and, in addition, the degree of reproducibility of visual microscopy was low.

Point-counting has been shown to be a very accurate method of assessing the relative proportions of different tissue components (Dunnill, 1968). The application of point-counting to aspiration marrow biopsies presents particular problems. The specimen is fragmented, and the cellularity of the fragments is not randomly distributed because of their different rates of sedimentation during fixation and processing. The primary purpose of this paper is to describe a simple point-counting procedure that permits accurate assessment of bone marrow cellularity. The results are correlated with those obtained with a Quantimet 720 image-analysing computer.

\section{Material and methods}

One hundred unselected bone marrow biopsies were retrieved from the files of the Department of Pathology, Ninewells Hospital and Medical School.

Received for publication 11 January 1978
These specimens had been fixed and processed to paraffin in a standard way and embedded in Peel-AWay embedding moulds (Peel-A-Way Scientific, California, USA; size S22). These result in paraffin blocks that, on sectioning, have a cut surface area of approximately $20 \times 20 \mathrm{~mm}$. From each block sections were cut at a microtome setting of $7 \mu \mathrm{m}$, and in three cases sections $200 \mu \mathrm{m}$ apart were obtained from the entire block. The sections were stained with Mayer's haemalum and eosin and mounted in synthetic resin.

An area of graph paper $\mathbf{4 0} \times \mathbf{4 0} \mathrm{mm}$ scaled in 10, 5 , and $1 \mathrm{~mm}$ was photographed and reduced to produce a negative $20 \times 20 \mathrm{~mm}$ scaled in $5,2.5$, and $0.5 \mathrm{~mm}$ : this was then contact-printed onto Kodak fine grain positive film to produce photographic grids that could be superimposed on the marrow preparations.

A graticule $(10 \times 10 \mathrm{~mm})$ with 121 intersection points was fitted in a $\times 6.3$ focussing eyepiece; the four corner intersections were ignored and the remaining 117 were used for point-counting. With a $\times 40$ objective, the image in the eyepiece graticule was most of the content of the smallest $(0.5 \mathrm{~mm})$ square in the photographic grid.

\section{POINT-COUNTING METHOD}

The photographic grid was placed over the marrow preparation and positioned so that the quadrants labelled A, B, C, D (Fig. 1) each contained approximately the same amount of marrow; the grid was then secured to the slide with narrow strips of adhesive tape.

Point counts were made in each quadrant A, B, $C$, and D. Within each quadrant the method of selecting fields for point-counting depended on the total area of the marrow sample. If the sample was large, fields nearest the centre of the $5 \mathrm{~mm}$ squares labelled I, II, III, IV were chosen; in a small sample, 


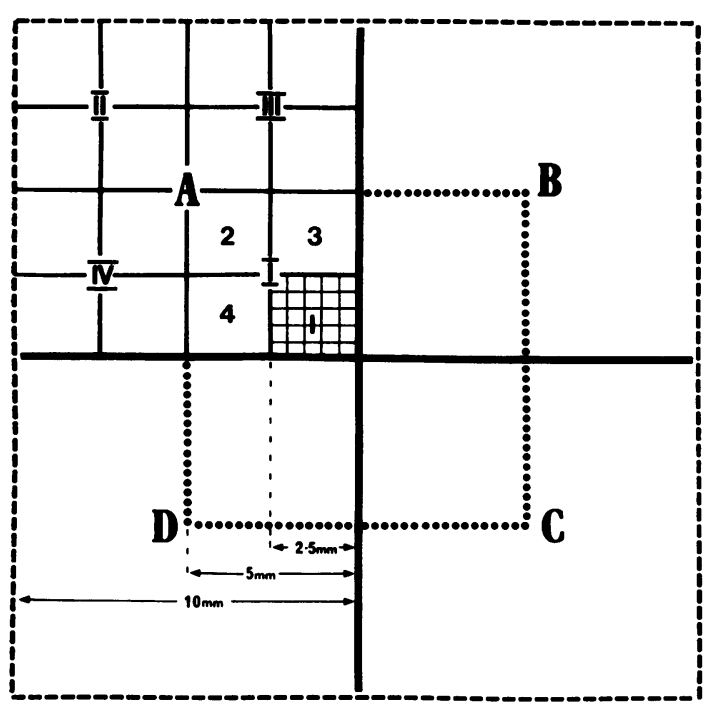

Fig. 1 Photographic grid, $20 \times 20 \mathrm{~mm}$, scaled in $5,2.5$, and $0.5 \mathrm{~mm}$. Square $I$ in quadrants $B, C$, and $D$ is shown by the dotted lines.

where the marrow was confined to the innermost $5 \mathrm{~mm}$ square labelled $I$ in each quadrant, fields nearest to the centre of the $2.5 \mathrm{~mm}$ squares labelled 1, 2, 3, 4 were chosen.

A minimum total of 600 points were counted. The assessment was based on an equal number of fields from each quadrant or all of the marrow specimen. The number of fields within which counts were made varied, depending on the degree of fragmentation of the marrow sample, but ordinarily did not exceed four in each quadrant A, B, C, D. For each field, the number of points lying on cell nuclei, cytoplasm, erythrocytes, and fat spaces were separately recorded using multiple tally counters. Erythrocytes at the periphery of marrow fragments or in large clefts within them were excluded because it was considered that they were derived from peripheral blood. The counts on marrow tissue for each field were summed, and the totals for cell nuclei, cytoplasm, erythrocytes, and fat were expressed as percentages.

\section{MEASUREMENTS WITH THE QUANTIMET 720}

The Quantimet 720 image analysing computer system used in this study comprised a Leitz Orthoplan microscope with Auto Focus; a Plumbicon Image Scanner with Auto Shade Corrector; a Variable Frame; a 1D Auto Detector and two 2D Amenders; an MS3 Standard Computer; a ClassifierCollector; a Calculator Field-Feature Interface; and a Hewlett-Packard 9810A Calculator. All measure- ments were made using a $\times \mathbf{4 0}$ objective and a $\times 10$ eyepiece.

Measurements of bone marrow cellularity were made independently on the same haemalum and eosin preparations used for visual point-counting. In place of the photographic grid, to facilitate the systematic selection of fields, two intersecting lines were drawn on the coverglass with a fine mapping pen and drawing ink so that approximately the same amount of marrow was contained in each quadrant. Within each quadrant three fragments of marrow, each large enough to fill the Quantimet 720 field, were selected for measurement in a random manner. Exceptionally, when the biopsy was particularly fragmented, it was found necessary to use the Variable Frame to reduce the area of the Quantimet 720 field by half. Care was taken to exclude peripheral blood from the measurements.

The method of using the Quantimet 720, in this instance, was a manual one: as each field was located, the controls of the 2D Detector were manipulated by hand, and the area was measured in 'picture-points' at three different detection levels corresponding to the darkly stained cell nuclei, the paler stained cytoplasm, and the unstained fat spaces. Because of the similarity of their staining, erythrocytes could not be distinguished from other cytoplasmic structures. Small artefactual cracks that would otherwise have been included in the measurement of the larger fat spaces were eliminated by using the two 2D Amenders in series. The image was eroded until the cracks disappeared and then dilated by the same number of 'picture-points' so that the fat spaces were restored to their original size. The Hewlett-Packard Calculator was programmed to calculate and print the running and average areas occupied by nuclei, cytoplasm, and fat as percentages of the total. The principles of working of the Quantimet 720 and other automated image analysing systems have been reviewed by Hougardy (1974). According to Fisher (1971), the area of a roughly circular feature of diameter $1 / 20$ th of the diagonal $D$ of the Quantimet 720 screen is measured to an accuracy better than $2 \%$, and that of a feature of $N$ diameter $1 / 10$ th of the screen diagonal to within $0.5 \%$. In applying the Quantimet 720 to the measure- $N$ ment of bone marrow cellularity, results reproducible $\underset{\omega}{ }$ to within $2 \%$ were consistently obtained.

\section{Results}

With visual point-counting, bone marrow cellularity, expressed as a percentage, was the sum of the

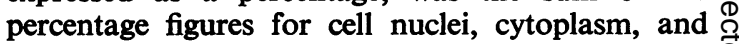
erythrocytes. It ranged from 21 to $99 \%$ in $100 \stackrel{\mathbb{Q}}{\varrho}$ specimens. In the case of the Quantimet 720 data 


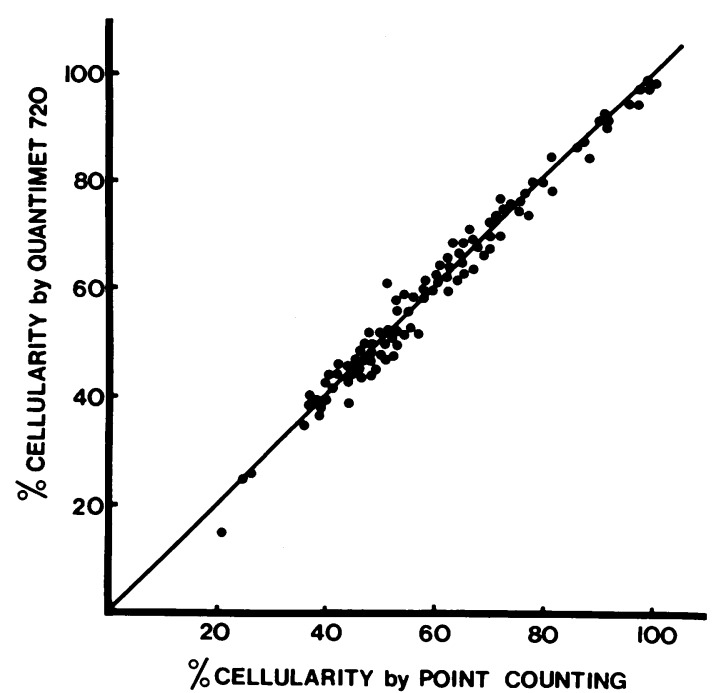

Fig. 2 Percentage cellularity as obtained by the visual point counting method and the Quantimet 720 ( $r=0.98$, $y=0.996 x+0.927)$.

in which erythrocytes were included in the measurement of cytoplasm, percentage cellularity was obtained by summing the figures for cell nuclei and cytoplasm. The results were closely similar (always within $5 \%$ ) to those obtained by visual pointcounting (see Fig. 2). Similarly, the correlation for cell nuclei, cytoplasm, and fat assessed separately was good.

The reproducibility of the point-counting method was tested by carrying out counts on four marrow preparations with a range in cellularity on six separate occasions. Percentage cellularity on each occasion was within $5 \%$ of the original result (mean coefficient of variation $=2 \cdot 6 \%$ ).

Variability within marrow samples was tested by carrying out point-counts with the Quantimet 720 on three random biopsies sectioned throughout the entire block at levels $200 \mu \mathrm{m}$ apart. In all cases percentage cellularity at all levels in each biopsy was within $5 \%$ of the result obtained at the first level (mean coefficient of variation $=5 \cdot 1 \%$ ).

\section{Discussion}

Objective methods of measuring the cellularity of bone marrow biopsies have occasionally been used in the past, the most popular being the volumetric method. This measures the myeloid-erythroid layer (buffy-coat) as a percentage of the total volume of aspirate. Because of dilution of the sample with peripheral blood (which may amount to $40-100 \%$ of the total volume (Berlin et al., 1950)), the method is subject to gross inaccuracy. Berman and Axelrod (1947) and Sturgeon (1951) used a Whipple eyepiece to obtain an assessment of marrow cellularity, but there is considerable observer error associated with this method.

The principles of point-counting have been reviewed by Dunnill (1962). Essentially, the number of points that fall on each component in a tissue section is proportional to the area occupied by that component and, from the theorem of Delesse, to its volume. The accuracy of the method in respect of a particular tissue component is dependent upon the volume density of the component and the number of points counted (Weibel, 1963). Thus, with a cellularity between 25 and $100 \%$ and counting 600 points the relative error will be $5 \%$, and $10 \%$ if the cellularity is between 7 and $25 \%$.

Point-counting has been used for the assessment of marrow cellularity in the iliac crest (Hartsock $e t$ al., 1965) and the second lumbar vertebra (Dunnill et al., 1967). However, in both of these studies blocks of marrow were obtained post mortem and the investigators did not have the problem of assessing cellularity in fragmented pieces of marrow with different rates of sedimentation. This problem was solved by point-counting the same number of fragments in each quadrant or in all of the fragments. The visual point-counting method described in this paper has a number of advantages. It requires no expensive apparatus. It is simple and quick, taking approximately 15 minutes for the assessment of one biopsy. The error is about $5 \%$ and the results are reproducible, so it should now be possible to assess the clinical significance of moderately hypocellular marrows. In addition, unlike previously described point-counting techniques, the results have been compared with those of the Quantimet 720, thus providing another measure of the accuracy of the results.

We are grateful to Dr A. S. Todd for suggesting that we undertake this project, to Professor J. S. Beck, Dr A. S. Todd, and Dr H. B. Goodall for reviewing the script, to Mrs Sheila Gibbs for photographic assistance, to Mr E. Wilton for technical help, and to Mrs I. M. A. Bloomer for typing the manuscript.

\section{References}

Berlin, N. I., Hennessy, T. G., and Gartland, J. (1950). Sternal marrow puncture: the dilution with peripheral blood as determined by $\mathrm{P}^{32}$ labeled red blood cells. Journal of Laboratory and Clinical Medicine, 36, 23-28.

Berman, L., and Axelrod, A. R. (1947). Evaluation of volumetric data obtained by centrifugation of aspirated sternal marrow of adults. I. Estimation of relative fat 
content. American Journal of Clinical Pathology, 17, 551-556.

de Gruchy, G. C. (1970). Clinical Haematology in Medical Practice, 3rd edition, pp. 249-250. Blackwell, Oxford. Dunnill, M. S. (1962). Quantitative methods in the study of pulmonary pathology. Thorax, 17, 320-328.

Dunnill, M. S. (1968). Quantitative methods in histology. In Recent Advances in Clinical Pathology, Series V, edited by S. C. Dyke, pp. 401-416. Churchill, London.

Dunnill, M. S., Anderson, J. A., and Whitehead, R. (1967). Quantitative histological studies on age changes in bone. Journal of Pathology and Bacteriology, 94, 275-291.

Fisher, C. (1971). The new Quantimet 720. The Microscope, 19, 1-20.

Hartsock, R. J., Smith, E. B., and Petty, C. S. (1965). Normal variations with aging of the amount of hemopoietic tissue in bone marrow from the anterior iliac crest. American Journal of Clinical Pathology, 43, 326-331.

Hougardy, H. P. (1974). Instrumentation in automatic image analysis. The Microscope, 22, 5-26.

Kurnick, J. E., Ward, H. P., and Block, M. H. (1972). Bone marrow sections in the differential diagnosis of polycythemia. Archives of Pathology, 94, 489-499.

Morley, A., and Blake, J. (1975). Observer error in histological assessment of marrow hypocellularity. Journal of Clinical Pathology, 28, 104-108.

Sturgeon, P. (1951). Volumetric and microscopic pattern of bone marrow in normal infants and children. III. Histologic pattern. Pediatrics, 7, 774-781.

Weibel, E. R. (1963). Morphometry of the Human Lung. Springer, Berlin.

Requests for reprints to: Dr D. O. Ho-Yen, Haematology Section, Department of Pathology, Ninewells Hospital, Dundee DD2 1UB.

\section{Reports and Bulletins prepared by the Association of Clinical Biochemists}

The following reports and bulletins are published by the Association of Clinical Biochemists. They may be obtained from The Publishing Department, British Medical Journal (ACB Technical Bulletins), B.M.A. House, Tavistock Square, London WC1H 9JR. Overseas readers should remit by British Postal or Money Order.

SCIENTIFIC REVIEWS (price $f 1 \cdot 00 / \$ 2.00$ each)

1 The assessment of thyroid function March 1971 F. V. FLYNN and J. R. HOBBS

2 Renal function tests suitable for clinical practice January 1972 F. L. MITCHELL, N. VEALL, and R. W. E. WATTS

3 Biochemical tests for the assessment of fetoplacental function May 1975 C. E. WILDE and R. E. OAKEY

4 Test of exocrine pancreatic function March 1977 A. H. GOWENLOCK

TECHNICAL BULLETINS (price $£ 1 \cdot 00 / \$ 2.00$ each)

22 Bilirubin standards and the determination of bilirubin by manual and technicon AutoAnalyzer methods January 1971 BARBARA BILLING, RUTH HASLAM, and $\mathrm{N}$. WALD

23 Interchangeable cells for spectrophotometers and fluorimeters September 1971 s. S. BROWN and A. H. GOWENLOCK

24 Simple tests to detect poisons March 1972 B. w. MEADE et al.

25 Blood gas analysers May 1972 K. DIXoN

26 Kits for enzyme activity determination September 1972 S. B. ROSALKI and D. TARLOW

27 Assessment of pumps suitable for incorporation into existing continuous flow analytical systems November 1972 A. FLECK et al.
28 Routine clinical measurements of transferrin in human serum September 1973 K. DIXON

29 Control materials for clinical biochemistry (5th edition) September 1973 J. F. STEVENS

30 Notes on the quality of performance of serum cholesterol assays September 1973 S. S. BROWN

31 Determination of uric acid in blood and in urine July 1974 R. W. E. WATTS

32 A survey of amino acid analysers readily available in the United Kingdom September 1974 J. e. CARLYLE and P. PURKISS

33 Definitions of some words and terms used in automated analysis November 1974 A. FLECK, R. ROBINSON, S. S. BROWN, and J. R. HOBBS

34 Measurement of albumin in the sera of patients January 1975 LINDA SLATER, P. M. CARTER, and J. R. HOBBS

35 Investigation of the validity of temperature correction factors for serum aspartate and alanine transaminases March 1975 S. B. ROSALKI et al.

36 Factors influencing the assay of creatinine November 1975 J. G. H. COOK

37 A survey of enzyme reaction rate analysers readily available in the United Kingdom July 1977 R. A. SAUNDERS and R. F. BURNS

38 Transport of specimens for clinical chemistry analysis November 1977 P. WILDING, J. P. ZILVA, and C. E. WIIDE

39 A scheme for the evaluation of diagnostic kits May 1978 P. H. LLOYD 